\title{
A systematic approach for assessment of renewable energy using analytic hierarchy process
}

\author{
Gerçek Budak, Xin Chen*', Serdar Celik and Berk Ozturk
}

\begin{abstract}
Background: Cities around the world face a great challenge in establishing a long-term strategy for the development of energy alternatives. Previous research tried to identify renewable energy across many different cities. Because each city has unique characteristics in terms of geographic and environmental conditions, population, economic development, and social and political environment, the most sustainable energy source for one city might be the least sustainable for another.

Methods: This research develops and implements a systematic approach to assess renewable energy and identify the energy alternatives for a city using the analytic hierarchy process. The methodology integrates experts' input and data analytics and helps decision-makers form long-term strategies for renewable energy development.

Results: The decision support system is applied to three cities, Chengdu in China, Eskisehir in Turkey, and Chicago in the United States of America. Results show that improving energy efficiency and development of solar and wind energy are the most preferred energy alternatives whereas nuclear and hydroelectric are the least preferred energy alternatives for these three cities.

Conclusions: The results of this study are in line with decades of research and development in energy alternatives and show a clear direction for the future development of energy alternatives around the world. There are differences in the rankings of energy alternatives for different cities, indicating that it is necessary to apply the decision support system developed in this study to help form customized energy strategies for cities with unique characteristics.
\end{abstract}

Keywords: Analytic hierarchy process, Multi-criteria decision-making, Renewable energy, Sustainability

\section{Background}

\section{Motivation, challenges, and objective}

As energy demand increases over time in many places, countries around the world and local governments diversify investment in a variety of energy sources to meet the demand [1]. Fossil fuels such as oil and natural gas are reliable energy sources, but are not sustainable and cause significant and irreversible damage to the environment in the long term in addition to their immediate damage such as fine dust emissions due to burning oil and mercury emissions caused by coal combustion. Renewable energy alternatives such as solar and wind are

\footnotetext{
* Correspondence: xchen@siue.edu

Department of Mechanical and Industrial Engineering, Southern Illinois University Edwardsville, Edwardsville, IL 62026-1805, USA
}

widely available and may be explored to meet part of the demand. In addition, improving the energy efficiency of existing applications is a cost-effective way to help meet the demand without significant increase in energy production [2].

Development of energy alternatives to fossil fuels faces a number of challenges [3]. First, several alternatives such as nuclear, biomass, solar, wind, and hydroelectric are available. A municipality has limited resources and cannot invest in all alternatives simultaneously and equally [1]. It is difficult to predict which energy alternatives will be most beneficial in the long term and determine which alternatives should be invested and the amount of investment. Secondly, the development of energy alternatives depends on many factors such as 
geographic conditions, population, societal needs, and politics. An energy alternative that is well suited for one city may be the worst choice for another city. Thirdly, there are many criteria such as cost and security that dictate the selection of energy alternatives. Which criteria should be included in the decision process for comparing energy alternatives and how to weigh different criteria need to be analyzed.

This study applies the analytic hierarchy process (AHP) and develops a systematic approach and a decision support system to assess energy alternatives and help municipalities select the most suitable alternatives. The methodology is implemented to analyze energy alternatives for three cities representing Asia, Europe, and North America. Results show that the energy alternatives chosen by the decision support system are reasonable and well justified. The AHP may be used to assess energy alternatives for other cities by computing total scores and rankings of alternatives using expert input. The methodology developed in this study may be adapted to general multi-criteria decision-making problems involving expert input.

\section{Literature review}

Renewable energy has become an inseparable part of sustainable economic development, and numerous studies were conducted to determine the investment strategies in renewable energy. Lee and Zhong [3] presented a study on developing a holistic strategy for renewable energy investment, which includes three steps of analyzing (a) economics and renewable energy policies, (b) renewable energy fields that exhibit more attractive investment opportunities, and (c) most promising renewable energy technologies for prospective investors. Aguilar and Cai [4] investigated the likelihood of opportunities for renewable energy private investments in the USA. The analysis showed that solar and wind energy was ranked at the top while grass and wood-based energy alternatives were at the bottom of the alternatives list.

Outside of the USA, Zhang et al. [5] studied a real options model for solar energy investment in China. The model investigated uncertain factors, including non-renewable energy cost, the market price of electricity, and $\mathrm{CO}_{2}$ costs, and evaluated the investment value and optimum timing for solar farm applications in China. It was found that increased level of subsidy, stabilized market, and promoting technological developments were major factors in leveraging investment. Simsek and Simsek [6] investigated the incentives for renewable energy in Turkey. It was stated that the deregulation of the electricity market and improved renewable energy legislations had encouraged growth in renewable energy investment and projects within the past few years. Kılkış $[7,8]$ developed a composite index to evaluate energy and environment systems in Mediterranean and Southeast European cities. Mattiussi et al. [9] developed a multi-objective optimization model and used the AHP to choose the most sustainable energy supply in Australia.

Romero et al. [10] studied the European Union (EU) plans for renewable energy. The research suggested that the recent success in the increase in renewable energy investment and installations was due to the public financial incentives. Spain was selected as a case study. Renewable options including wind, solar-thermal, photovoltaic, and biomass were studied. Financial support systems in Spain were also identified in the study. Another study on the European side was conducted by Bulavskaya and Reynès [11]. This study focused on macroeconomics and job creation potential of renewable energy technologies in the Netherlands. It was predicted that $0.85 \%$ of gross domestic product (GDP) would come from renewable energy applications by 2030. It was also estimated that 50,000 new full-time jobs would become available by then.

The research was conducted previously to compare and select renewable energy. Many municipalities, especially medium to large-size cities, however, face the challenge of how to identify the most suitable energy sources that are sustainable and cost-effective. There is a gap between the state-of-the-art research in renewable energy and how to customize the research outcome for the development and implementation of renewable energy in cities around the world. Complex decisions about renewable energy often involve intangible and implicit information, which may be quantified using tangible and explicit values to help make informed decisions [12]. The AHP is a measurement technique that performs pairwise comparisons of decision criteria and rank decision alternatives using expert knowledge. The AHP identifies inconsistencies in experts' input through consistency check; inconsistent expert input is excluded from analysis of the decision problem to ensure the validity of expert knowledge. In addition to inconsistencies, scaling of experts' assessment of decision alternatives for different criteria affects decision-making and its outcome [13]. The AHP enables experts to adjust their assessment through a reaffirmation process and finetune their assessment for unbiased decision-making.

Since the AHP was first developed in 1980s, it has been applied to many applications for decision-making [14]. Several studies focused on using the AHP for the planning of renewable and sustainable energy (e.g., [15-24]). In the context of renewable energy, various studies targeted specific energy sources. For example, Sindhu et al. [25] prioritized challenges in the growth of solar energy in India using the AHP. Uyan [26] used the AHP to select solar farm sites in Turkey. Papalexandrou et al. [27] used the AHP to compare biofuels and fossil fuels and determine 
which types of biofuel should be chosen. Okello et al. [28] used the AHP to evaluate bioenergy alternatives in Uganda. Choudhary and Shankar [29] discussed how the AHP could be used to select thermal power plant locations in India.

In addition to planning of renewable energy and selection of specific renewable energy sources, the AHP was widely used in energy applications and beyond. For example, several studies focused on green supply chains and used the AHP to help select suppliers [30], seaports [31], and green electricity [32]. Other studies used the AHP to select wind observation station locations [33], allocate energy research and development resources [34], and compare water heating systems [35]. While there has been substantial research on renewable energy planning and energy source selection using the AHP, few studies combined these two directions and applied them to various geographical regions to determine the long-term energy strategies in these regions. Municipalities have unique characteristics, including natural resources, environmental conditions, population, industry activities, politics, and others, and experience different short-term and long-term trends of how these characteristics might evolve. The planning of energy production involves several actors (e.g., policy-makers and service providers) at different scales (e.g., local, regional, and national). A systematic approach is needed to enable a municipality to design a strategy for effectively and efficiently exploring energy alternatives.

The novelty of this article is twofold. First, this study integrates energy planning and energy source selection. Previous research focused on either the planning of a specific energy source such as wind or solar, or the selection of energy sources. This article integrates both and develops a systematic approach for long-term energy planning and selection of sustainable energy sources. Secondly, this study applies the AHP to help energy planning and selection of renewable energy for specific cities based on their unique characteristics. Previous research developed general methodologies for energy planning or selection of energy sources; these methodologies were not customized for municipalities and recommendations were often disconnected from realities.

\section{Methodology}

Many methods and multi-criteria decision-making approaches such as the AHP, analytic network process (ANP), and technique for order preference by similarity to ideal solution (TOPSIS), VIseKriterijumska Optimizacija I Kompromisno Resenje (VIKOR), and ELimination Et Choix Traduisant la REalité (ELECTRE) were developed to rank alternatives. The main contribution of this study is a systematic approach embedded in a decision support system that uses the AHP to rank different energy alternatives according to multiple criteria and determines the appropriate energy alternatives for a particular city. Decision-makers and stakeholders may use the outcome of the decision support system developed in this study to make informed decisions about the investment and implementation of energy alternatives for a city. Two sets of data, including weights for the assessment criteria and performance scores of energy alternatives for criteria, are collected, normalized, and analyzed in this study. Weights for criteria are determined through a survey of experts across multiple disciplines and performance scores are obtained through in-depth face-to-face interviews with energy domain experts who have intimate knowledge about cities of interest [12, 13].

This study answers a key research question "Which energy alternatives are the most suitable for a city given its location, recourses, population, political environment, and other factors?" The two main steps of this study are to determine (a) weights of criteria for the assessment of energy alternatives, and (b) performance scores of energy alternatives for each criterion and a city of interest. Previous research investigated several aspects in the assessment of renewable energy, including environmental concerns [18], incentives [6], investment strategies [3-5], jobs and economic development [11], and research development [34]. These perspectives may be grouped into five main criteria (Table 1). These five criteria correspond to four categories, including economy, technology, environment, and society, which were used to assess renewable energy in multi-criteria decision-making in the literature [36].

The four categories in Table 1, economy, technology, environment, and society, are the main categories that shape the strategical decisions of renewable energy deployment in cities [36]. The five assessment criteria in Table 1 are extracted from literature $[3-7,11,18,34]$ and belong to one or more of the four categories. Table 1 shows the mapping between the five assessment criteria and four assessment categories.

After the five criteria for the assessment of energy alternatives are identified based on literature review, the next step is to determine weights for each criterion using the AHP. The AHP obtains experts' input through pairwise comparisons of criteria and examines the consistency of comparisons provided by each expert. Consistent input from multiple experts are compiled and used to calculate the weights of criteria. These criteria are then used to assess energy alternatives for a particular city. For each criterion, 
Table 1 Five assessment criteria of energy alternatives

\begin{tabular}{lll}
\hline Criteria & Description & Categories \\
\hline Cost & Investment, maintenance and operating cost, and other life cycle costs & Economy \\
Maximum capacity & Installed capacity, reliability, and service life & Technology \\
Environmental impact & Pollution, emission, noise, land use, and consumer acceptance & Environment \\
Job creation & Job opportunities, economic impact, and regional development & Economy/society \\
Security & Risks, disruptions, and disasters & Technology/society \\
\hline
\end{tabular}

an expert is presented with multiple energy alternatives and the expert provides a performance score for each alternative for the criterion. The seven energy alternatives assessed in this study are efficiency, solar, wind, geothermal, biomass, nuclear, and hydroelectric. The first alternative, efficiency, indicates that investment may be made to improve energy efficiency of existing energy applications, and this is an investment alternative to other renewable energy. It is important to note that these seven energy alternatives are not mutually exclusive. One or more alternatives may be selected for a particular city depending on available resources. Table 2 summarizes the five criteria and seven alternatives. The expert's assessment of an alternative for a criterion is a performance score to be recorded in the cell at the intersection of the criterion and alternative in Table 2 .

Two criteria, cost and maximum capacity, are measurable and have units whereas the other three, environmental impact, job creation, and security, are a combination of tangible and intangible factors and are difficult to measure. The AHP solicits experts' assessment of the performance of energy alternatives for each criterion using a scale of 0-10 (Table 3). Suppose an expert is asked to assess the performance of energy alternative $\mathrm{X}$ for criterion $\mathrm{Y}$ in city $Z$, the expert answers the question "What would be the performance of $\mathrm{X}$ for $\mathrm{Y}$ if $\mathrm{X}$ is used in $\mathrm{Z}$ ?" and assigns a score between 0 and 10. A higher score indicates that $X$ performs relatively well in terms of $\mathrm{Y}$ if $\mathrm{X}$ is used in $\mathrm{Z}$, and a lower score indicates that $\mathrm{X}$ might not be a good choice for $\mathrm{Z}$ in terms of $\mathrm{Y}$.

Two surveys (questionnaires) are developed using the AHP [12, 37] to obtain experts' assessment. The first survey is used to determine the weights for the five criteria through pairwise comparisons. The survey is sent to multiple experts in the fields of renewable energy and energy applications. Responses from a large number of experts help remove or reduce bias in survey results. The second survey is used to obtain performance scores for different energy alternatives. This survey is completed through interviews with experts who not only are knowledgeable about renewable energy but also have a deep understanding of geographic, social, and environmental characteristics of a particular city. Several interviews may be conducted with the same expert to fine-tune the expert's assessment and confirm the performance scores. Similar to the first survey, it is also desirable to obtain responses from multiple experts for the second survey. Because the second survey does not involve pairwise comparisons and there are fewer experts who are both knowledgeable about renewable energy and characteristics of a city, one expert for each city is interviewed to complete the second survey.

Figure 1 shows the underlying hierarchical structure of two surveys whose results are used to rank and select renewable energy sources. The ranking of

Table 2 Assessment of energy alternatives

\begin{tabular}{|c|c|c|c|c|c|}
\hline \multirow{2}{*}{$\begin{array}{l}\text { Energy } \\
\text { alternatives }\end{array}$} & \multicolumn{5}{|c|}{ Criteria } \\
\hline & Cost & Maximum capacity & Environmental impact & Job creation & Security \\
\hline \multicolumn{6}{|l|}{ Efficiency } \\
\hline \multicolumn{6}{|l|}{ Solar } \\
\hline \multicolumn{6}{|l|}{ Wind } \\
\hline \multicolumn{6}{|l|}{ Geothermal } \\
\hline \multicolumn{6}{|l|}{ Biomass } \\
\hline \multicolumn{6}{|l|}{ Nuclear } \\
\hline Hydroelectric & & & & & \\
\hline
\end{tabular}


Table 3 Performance scores of criteria

\begin{tabular}{lll}
\hline Criteria & Scores & \\
\cline { 2 - 3 } & 0 & 10 \\
\hline Cost & Most expensive & Least expensive \\
Maximum capacity & Extremely low & Extremely high \\
Environmental impact & Most harmful to the environment & Small or negligible impact on the environment \\
Job creation & Net gain of job opportunities is small or negligible, & Substantial net gain of job opportunities \\
Security & or net loss of job opportunities & \\
& Vulnerable to incidents and/or catastrophic consequence & Resilient to incidents and the impact of an \\
& if incidents occur & incident is minimum
\end{tabular}

renewable energy may be conducted using a variety of methods such as the TOPSIS and data envelopment analysis (DEA), but the AHP is the most appropriate method for the analysis of problems with hierarchical structures similar to that in Fig. 1. In addition, the AHP performs better than other methods in obtaining experts' response and check the consistency of each expert's response. The AHP may be applied to problems with $7 \pm 2$ factors [38]. This study uses five assessment criteria and the AHP is well suited for the analysis of renewable energy in this study.

\section{Applications of AHP to Chengdu, Eskisehir, and Chicago}

Three cities from Asia, Europe, and North America are selected to assess their energy alternatives using the AHP and help these cities develop long-term strategies for the applications of renewable energy. In Asia, Chengdu, a major city located in Western China with a population over 7.8 million, is selected to apply the AHP to assess renewable energy. Chengdu is close to (about 20 miles) the longest river, Yangtze River, in China. This provides Chengdu with great potential of hydroelectric and nuclear energy. The majority of Chengdu's electricity supply comes from coal. Chengdu does not have any nuclear power plants. One reason to choose China is that China has had nuclear power plants for several decades and has a strategic plan and the technology know-how to build more nuclear power plants.

In Europe, Eskisehir, located in the northwest of Turkey and interconnecting Ankara and other major cities, is selected because Turkey is a fast-developing country with ever-increasing energy demand and Eskisehir in particular faces the challenge of energy shortage. Eskisehir has a great potential of developing solar, wind, and biomass energy and serves as an energy distribution center for the surrounding region [39]. In addition, low population density and increasing government support make Eskisehir an ideal city for this study. In North America, Chicago, one of the largest and densely populated cities in the USA, is selected for this study. Chicago is located on the shores of Lake Michigan and close to several rivers. The State of Illinois where Chicago is located has a high-level of agricultural activities [40]. Chicago is in need of additional energy and has a great potential for developing nuclear, wind, and biomass energy. In 2011, 56\% of Chicago's energy needs were met by fossil fuels such as coal and natural gas [41].

Figure 2 describes the steps in the AHP process applied in this study. The two questionnaires are

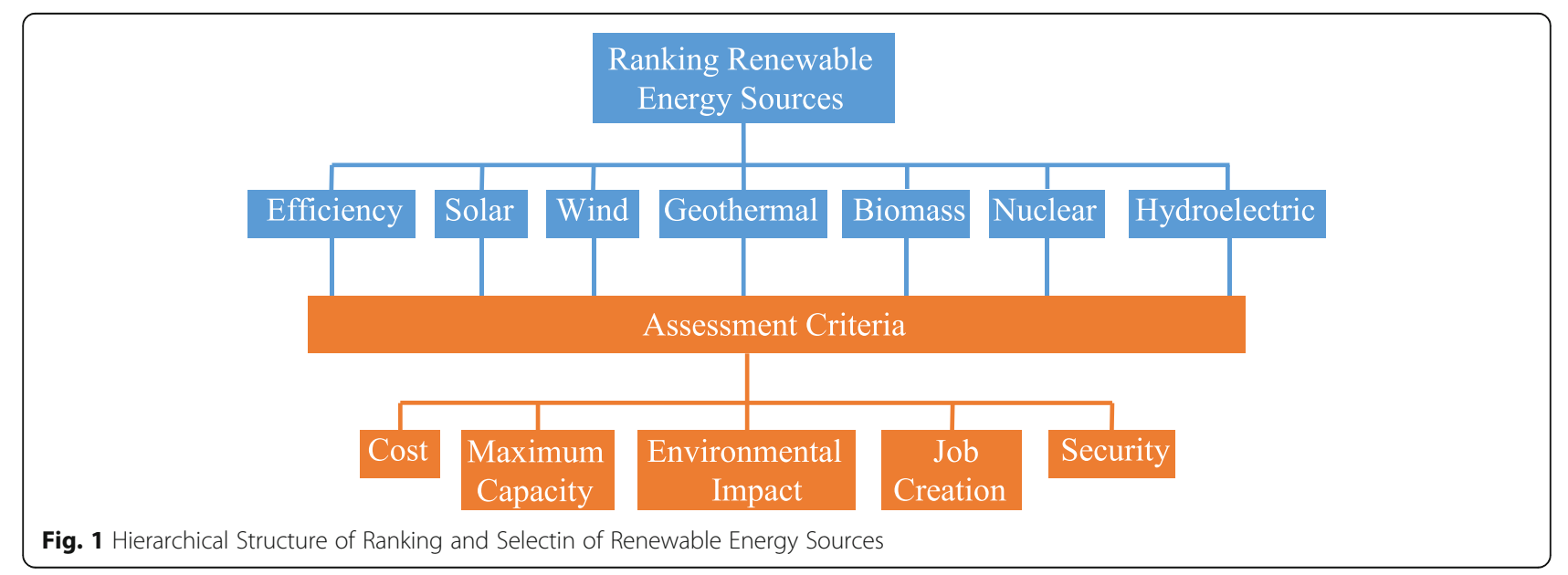




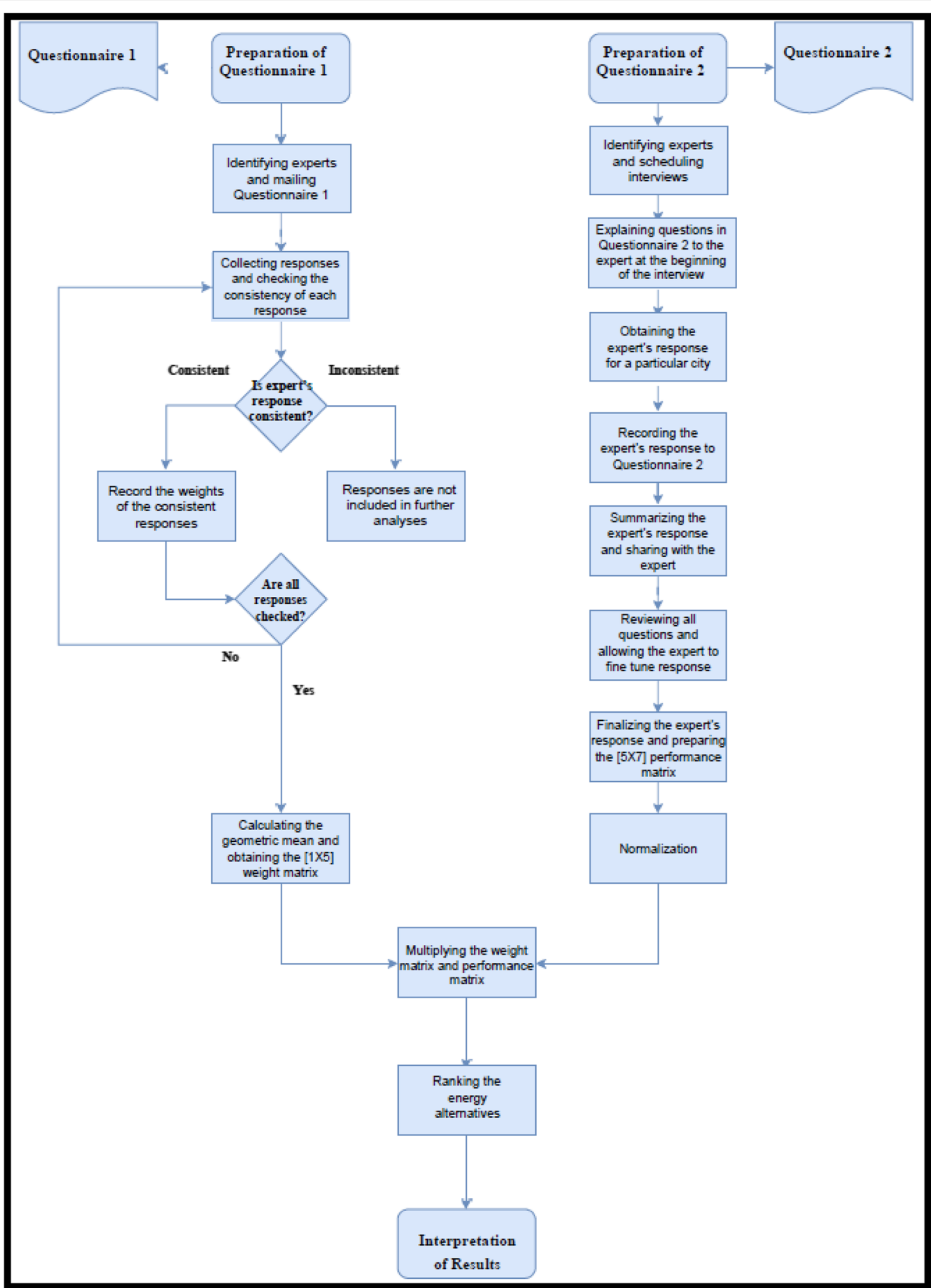

Fig. 2 Flowchart of the AHP Process 
prepared according to the rules of AHP. Appendix 1 shows a sample question in Questionnaire 1 and Appendix 2 shows a sample question in Questionnaire 2. The two questionnaires are prepared to obtain weights of the five assessment criteria and performance of renewable energy for each assessment criterion. The first questionnaire is developed according to the AHP methodology with pairwise comparisons (Appendix 1). The second questionnaire is used to obtain experts' assessment of renewable energy for each criterion. The normalization step in Fig. 2 guarantees that the summation of performance scores of any energy alternative is one. The second questionnaire must be carefully administered to experts with substantial knowledge about a city and its renewable energy sources in terms of their cost, capacity, environmental impact, job creation, and security. One expert is identified to complete the second questionnaire for each city. The second questionnaire is administered to the expert repeatedly and the expert's response is fine-tuned several times to achieve high accuracy and consistency.

\section{Results}

Experts surveyed in this study are from diverse fields. Questionnaire 1 was sent to 110 experts and 38 of them have provided feedback. Figure 3 summarizes areas of expertise of the 38 experts. Each expert's response is analyzed using the AHP consistency test [13]. Among the 38 experts, 23 experts have provided responses that are consistent in terms of pairwise comparisons of criteria in Questionnaire 1 . In other words, $61 \%$ of responses are consistent; this percentage is lower than expected.
One reason for the low consistency rate is the number of criteria. This study investigates five assessment criteria, which require 10 pairwise comparisons. Experts may be prone to inadvertent mistakes in performing a large number of pairwise comparisons. Another reason for the low consistency rate is that Questionnaire 1 is completed by experts online. There is no real-time interaction that can further explain the questions in the questionnaire and guide the expert through the survey. Appendix 3 summarizes experts' responses to Questionnaire 1. The geometric means of the responses from the 23 experts are calculated and normalized (Table 4).

Weights in Table 4 together with performance scores obtained from Questionnaire 2 are used to calculate an overall score for each energy alternative for a particular city. Weights in Table 4 are independent of geographical locations or municipalities whereas experts' assessment in response to Questionnaire 2 is for a particular location or municipality. To calculate the independent weight for a criterion, every expert's response to a question "Which one of the two criteria is more important than the other, and at what level?" is given a scale between "1" and "9" (Table 5). For example, if criterion $\mathrm{X}$ is more important than criterion $\mathrm{Y}$ and it has strong importance, then criterion $\mathrm{X}$ has a scale of "5" (Table 5) and criterion $Y$ has a scale of " $\frac{1}{5}$," which is the reciprocal of " 5 ." Responses from multiple experts for each criterion are then aggregated to calculate the geometric mean, which is then normalized to compute the weight for the criterion.

Questionnaire 2 is completed by three experts each of which is an expert for one of the three cities

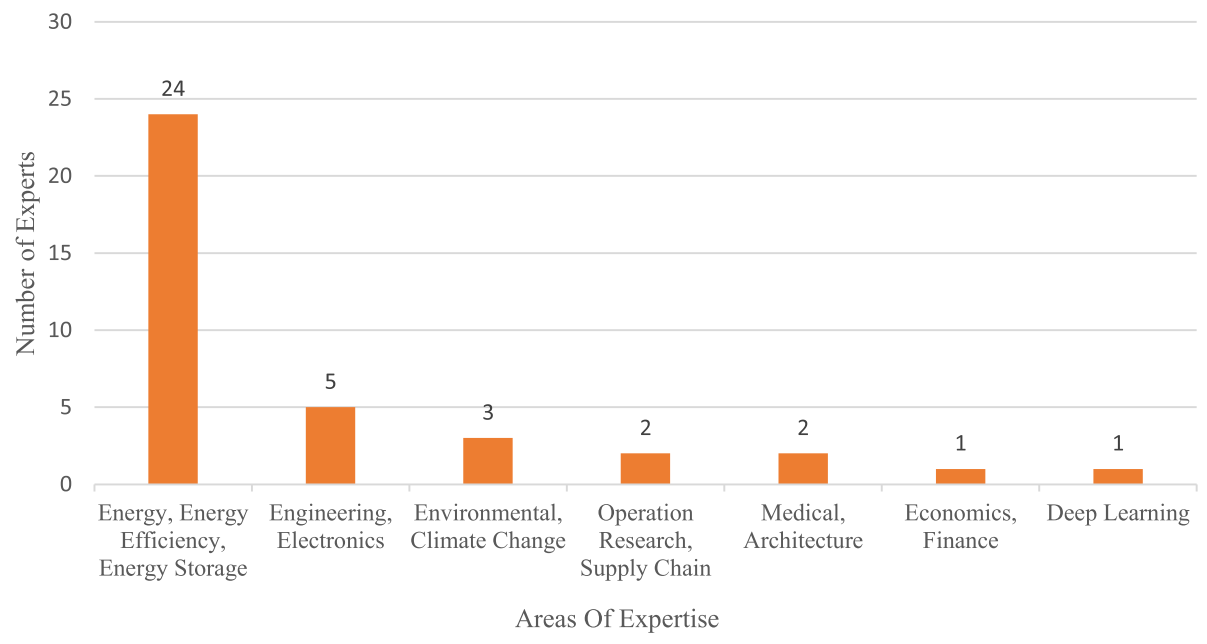

Fig. 3 Experts Completing Questionnaire 1 
Table 4 Weights of the criteria according to experts

\begin{tabular}{llllll}
\hline & \multicolumn{3}{l}{ Criteria } & & \\
\cline { 2 - 6 } & Cost & $\begin{array}{l}\text { Maximum } \\
\text { capacity }\end{array}$ & $\begin{array}{l}\text { Environmental } \\
\text { impact }\end{array}$ & $\begin{array}{l}\text { Job } \\
\text { creation }\end{array}$ & Security \\
\hline Weight & 0.14 & 0.12 & 0.23 & 0.11 & 0.15 \\
\hline
\end{tabular}

selected for this study, Chengdu, Eskisehir, and Chicago. Experts' responses to Questionnaire 2 are obtained through face-to-face interviews. At the beginning of an interview, the expert receives a detailed briefing on questions and the meaning of scores in Questionnaire 2. During the interview, the expert provides a score for each energy alternative and criterion. Scores are between 0 and 10 (Table 3 in the "Results" section). After the expert completes all questions in Questionnaire 2, the expert is shown the completed response and is asked to complete all questions again to allow the expert to confirm and fine-tune the response. Table 6 summarizes the results of Questionnaire 2 after responses from all three experts are collected and normalized. In Table 6, "C" represents cost, "MC" represents maximum capacity, "EI" represents environmental impact, "JC" represents job creation, and " $\mathrm{S}$ " represents security. Results in Tables 4 and 6 are then aggregated through matrix multiplications to calculate a weighted total performance score for each energy alternative and city (Table 7).

\section{Discussion}

For each city in Table 7, the sum of scores for different energy alternatives in a column is 1 . Solar energy is ranked at the top for Chengdu, which has a moderate amount of sunshine. The cost of developing solar energy (e.g., solar panels) in China is low because of China's strong manufacturing and relatively low labor cost. Although solar energy does have negative environmental impact (e.g., pollution in the process of producing solar panels), this impact is considerably smaller compared to other energy alternatives. Nuclear energy is ranked the last for

Table 5 Scales for calculating weights for criteria [13]

\begin{tabular}{ll}
\hline Scale & Interpretation/choice in Questionnaire 1 \\
\hline 1 & Equally important \\
3 & Moderate importance \\
5 & Strong importance \\
7 & Very strong importance \\
9 & Extreme or absolute importance \\
$2,4,6,8$ & Intermediate values \\
\hline
\end{tabular}

Chengdu. Although China has been building nuclear power plants for decades and has a long-term plan to build more, it does not have any nuclear power plant in West China where Chengdu is located. China has significantly slowed down the pace of building new nuclear power plants and has been more and more focused on developing renewable energy alternatives in recent years.

Although one of the main energy sources for Eskisehir is geothermal energy, it is ranked the fifth among all energy alternatives by the experts. There are several reasons why geothermal energy is ranked low. First, the development of additional geothermal plants is costly. Secondly, due to a large number of geothermal facilities already in Eskisehir, their collective capacity has almost reached the maximum. Thirdly, the expert is familiar with Eskisehir and concludes that geothermal energy causes significant damage to the environment. In addition to geothermal, nuclear energy is not acceptable ("0" total score in Table 7) for Eskisehir due to water shortage and technical challenges of building nuclear power plants. The top three energy alternatives for Eskisehir are improving efficiency, solar, and wind. Eskisehir is a large city in Turkey. Similar to Chicago discussed next, energy efficiency is extremely beneficial for large cities.

For Chicago, energy efficiency is ranked the first with the highest score 0.201 among all energy alternatives. Chicago is one of the largest cities in the USA and is expected to have a great potential for improving energy efficiency. Nuclear and hydroelectric energy rank close to the bottom because both require a large investment ("0" in Table 6 for cost), negatively impact the environment (low scores in Table 6), and are much less secure (low scores in Table 6) than other energy alternatives. The scores and rankings for Chicago are consistent with results from many studies on renewable energy.

Table 4 clearly shows that environmental impact (weight is 0.23) and security (weight is 0.15) are the two most important criteria for the assessment of energy alternatives. As climate change and environment concerns become the forefront of energy strategy and many other long-lasting economic development decisions, there is a consensus that the quality of life and sustainable development are more important than short-term economic gains. Energy alternatives that have less negative impact on environment and are more secure dominate other alternatives for long-term investment (Table 7).

The total scores and rankings of energy alternatives are computed using the AHP and experts' response to Questionnaires 1 and 2. The cores and 
Table 6 Performance scores of energy alternatives for three cities.

\begin{tabular}{|c|c|c|c|c|c|c|c|c|c|c|c|c|c|c|c|}
\hline \multirow{3}{*}{$\begin{array}{l}\text { Energy } \\
\text { alternatives }\end{array}$} & \multicolumn{15}{|c|}{ Experts for three cities and criteria } \\
\hline & \multicolumn{5}{|c|}{ Chengdu } & \multicolumn{5}{|c|}{ Eskisehir } & \multicolumn{5}{|c|}{ Chicago } \\
\hline & $\mathrm{C}$ & MC & $\mathrm{El}$ & JC & S & $\bar{C}$ & $M C$ & $\mathrm{El}$ & $J C$ & S & C & $M C$ & $\mathrm{El}$ & $J C$ & S \\
\hline Efficiency & 9 & 2 & 9 & 1 & 10 & 9 & 9 & 10 & 2 & 10 & 10 & 7 & 9 & 6 & 10 \\
\hline Solar & 10 & 6 & 9 & 2 & 10 & 7 & 6 & 9 & 6 & 9 & 7 & 4 & 10 & 5 & 10 \\
\hline Wind & 7 & 3 & 8 & 3 & 9 & 5 & 8.5 & 8 & 5 & 8 & 3 & 5 & 10 & 5 & 9 \\
\hline Geothermal & 5 & 5 & 6 & 4 & 7 & 4 & 7 & 5 & 5.5 & 6 & 3 & 2 & 6 & 3 & 7 \\
\hline Biomass & 5 & 4 & 7 & 5 & 6 & 6 & 5 & 8.5 & 4 & 7 & 8 & 3 & 8 & 2 & 9 \\
\hline Nuclear & 1 & 10 & 2 & 9 & 1 & 0 & 0 & 0 & 0 & 0 & 0 & 10 & 5 & 10 & 2 \\
\hline Hydroelectric & 3 & 9 & 3 & 9 & 5 & 1 & 1 & 7 & 7 & 6.5 & 0 & 9 & 7 & 9 & 4 \\
\hline
\end{tabular}

rankings might vary if there are changes in the number of experts, experts' disciplines/background, and other factors. Weights in Questionnaire 1 are geometric means, which are not sensitive to the number of experts. It is expected that the total scores and rankings may change slightly if the number of experts varies or a different group of experts is surveyed. The methodology developed in this research provides detailed and well-justified rankings of different energy alternatives for a particular city based on experts' input and a systematic AHP. This methodology helps decision-makers form long-term energy strategies. Decision-makers may use the outcome of this decision support system as a starting point and take into consideration other factors such as budget, collaboration with adjacent municipalities, and stakeholders' common interest to adjust the priority of energy alternatives.

\section{Conclusions and future research}

This study develops and implements a systematic approach embedded in a decision support system to assess energy alternatives using the AHP. The methodology integrates expert knowledge and data

Table 7 Total performance scores and rankings of energy alternatives for three cities

\begin{tabular}{lllllll}
\hline $\begin{array}{llllll}\text { Energy } \\
\text { alternatives }\end{array}$ & \multicolumn{2}{l}{ Cities } & \multicolumn{3}{l}{ Chicago } \\
\cline { 2 - 7 } & \multicolumn{2}{l}{ Chengdu } & & Eskisehir & & 0.201 \\
\hline Efficiency & Second & 0.161 & First & 0.211 & First & 0.201 \\
Solar & First & 0.186 & Second & 0.194 & Second & 0.172 \\
Wind & Third & 0.153 & Third & 0.177 & Fourth & 0.145 \\
Geothermal & Fourth & 0.133 & Fifth & 0.139 & Seventh & 0.098 \\
Biomass & Fifth & 0.133 & Fourth & 0.162 & Third & 0.149 \\
Nuclear & Seventh & 0.102 & Seventh & 0 & Sixth & 0.112 \\
Hydroelectric & Sixth & 0.132 & Sixth & 0.117 & Fifth & 0.123 \\
\hline
\end{tabular}

analytics, and the output of the decision support system provides scores and rankings for a variety of energy technologies, which create a pathway and enable decision-makers to form long-term energy investment strategies for municipalities. The methodology and its implementation in this study may be expanded and adapted for other complex decisions that involve expert input and detailed analysis. Based on the analyses of the three cities in this study, Chengdu, Eskisehir, and Chicago, improving energy efficiency and development of solar and wind energy are the three most preferred energy alternatives whereas nuclear and hydroelectric are the least preferred energy alternatives. This result is in line with decades of research and development in energy alternatives and shows a clear direction for the future development of energy alternatives around the world. There are differences in the rankings of energy alternatives for different cities, indicating that it is necessary to apply the decision support system developed in this study to help form customized energy strategies for cities with unique characteristics.

Future research may focus on implementing the methodology to adjacent cities and generate a map for renewable energy investment, which can be used to coordinate the development of energy alternatives for a large region. In addition, the number of experts and the disciplines from which experts are selected, and the questions in the questionnaires, may be adjusted to further reduce potential bias. Fuzzy AHP and other methods may be used to model the uncertainty in experts' assessment of energy alternatives. Last but not least, the outcome of this study comprises of scores and rankings of energy alternatives, which may be input to a mathematical model that can be solved with additional constraints such as total budget to find the optimal investment strategy. 


\section{Appendix 1}

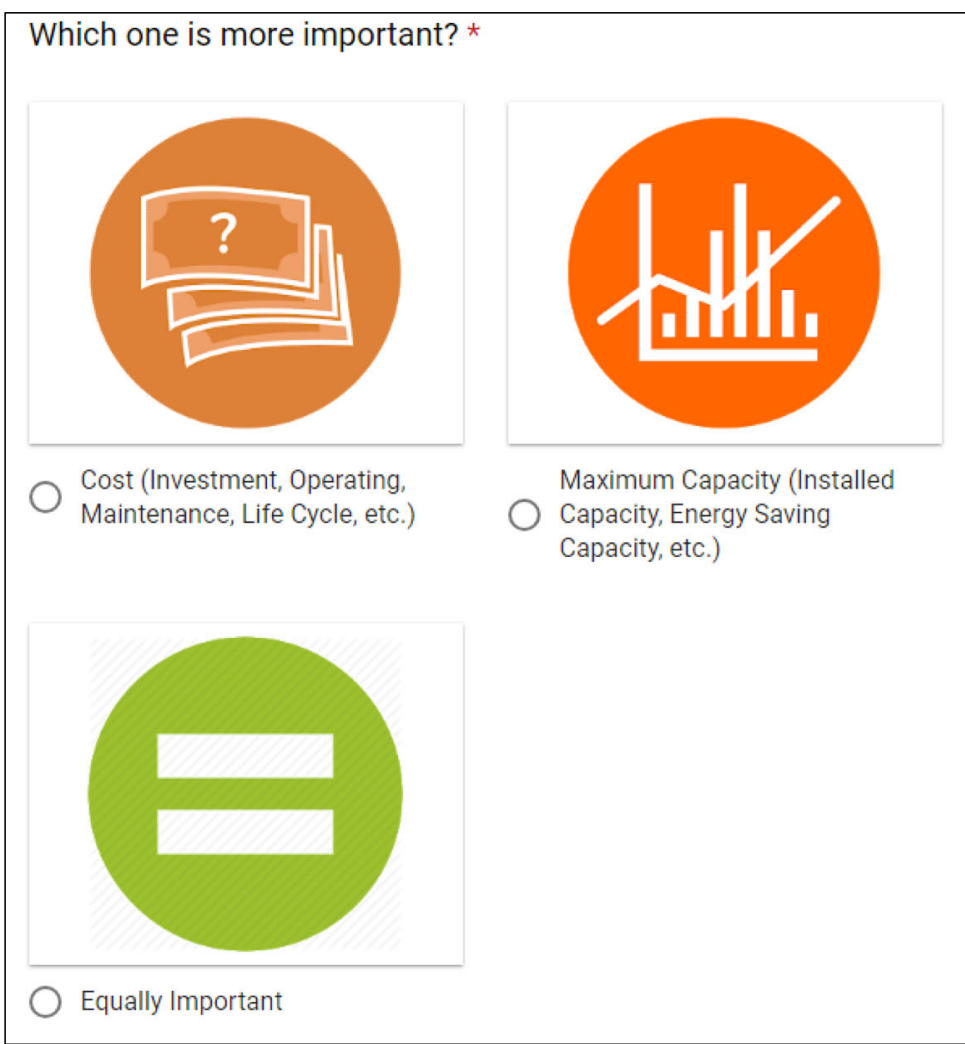

What is the importance level of the criterion based on your previous answer? *

Moderate Strong Very Strong Extreme
Cost Importance
Level
$\mathrm{O}$
O
O
O

Fig. 4 A Sample question in Questionnaire 1 


\section{Appendix 2}

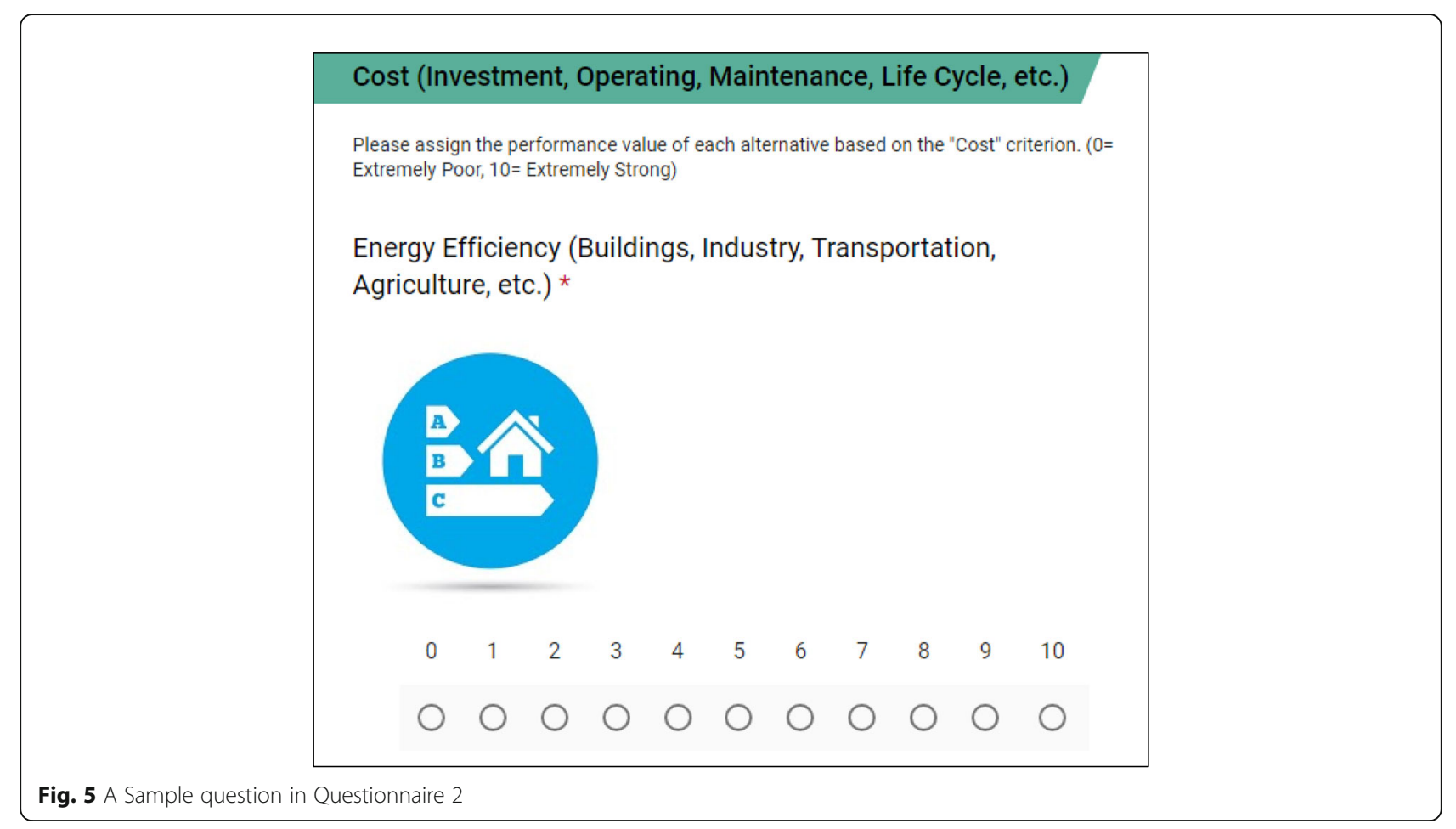




\section{Appendix 3}

Table 8 Experts' response to Questionnaire 1. Experts' response in bold indicates that the response is consistent in terms of pairwise comparisons of criteria. Experts' response in italic indicates that the response is inconsistent.

\begin{tabular}{|c|c|c|c|c|c|}
\hline \multirow[t]{2}{*}{ Experts } & \multicolumn{5}{|c|}{ Criteria } \\
\hline & Cost & Maximum capacity & Environmental impact & Job creation & Security \\
\hline 1 & 0.10 & 0.27 & 0.25 & 0.19 & 0.19 \\
\hline 2 & 0.22 & 0.06 & 0.05 & 0.05 & 0.61 \\
\hline 3 & 0.30 & 0.12 & 0.27 & 0.27 & 0.04 \\
\hline 4 & 0.18 & 0.03 & 0.38 & 0.14 & 0.26 \\
\hline 5 & 0.17 & 0.17 & 0.36 & 0.05 & 0.26 \\
\hline 6 & 0.22 & 0.46 & 0.14 & 0.15 & 0.03 \\
\hline 7 & 0.07 & 0.12 & 0.67 & 0.06 & 0.07 \\
\hline 8 & 0.13 & 0.11 & 0.25 & 0.04 & 0.48 \\
\hline 9 & 0.15 & 0.13 & 0.13 & 0.05 & 0.55 \\
\hline 10 & 0.19 & 0.05 & 0.55 & 0.17 & 0.05 \\
\hline 11 & 0.04 & 0.11 & 0.12 & 0.14 & 0.59 \\
\hline 12 & 0.05 & 0.08 & 0.41 & 0.05 & 0.41 \\
\hline 13 & 0.09 & 0.14 & 0.55 & 0.17 & 0.04 \\
\hline 14 & 0.07 & 0.12 & 0.58 & 0.11 & 0.12 \\
\hline 15 & 0.18 & 0.15 & 0.42 & 0.19 & 0.06 \\
\hline 16 & 0.08 & 0.05 & 0.25 & 0.30 & 0.32 \\
\hline 17 & 0.18 & 0.46 & 0.13 & 0.12 & 0.12 \\
\hline 18 & 0.14 & 0.15 & 0.38 & 0.11 & 0.22 \\
\hline 19 & 0.07 & 0.03 & 0.54 & 0.21 & 0.15 \\
\hline 20 & 0.13 & 0.04 & 0.46 & 0.14 & 0.23 \\
\hline 21 & 0.09 & 0.09 & 0.09 & 0.09 & 0.64 \\
\hline 22 & 0.24 & 0.18 & 0.38 & 0.12 & 0.08 \\
\hline 23 & 0.43 & 0.03 & 0.39 & 0.08 & 0.08 \\
\hline 24 & 0.29 & 0.04 & 0.31 & 0.31 & 0.05 \\
\hline 25 & 0.32 & 0.30 & 0.30 & 0.02 & 0.06 \\
\hline 26 & 0.08 & 0.08 & 0.69 & 0.08 & 0.08 \\
\hline 27 & 0.04 & 0.10 & 0.42 & 0.04 & 0.40 \\
\hline 28 & 0.06 & 0.10 & 0.25 & 0.10 & 0.50 \\
\hline 29 & 0.2 & 0.2 & 0.2 & 0.2 & 0.2 \\
\hline 30 & 0.11 & 0.11 & 0.54 & 0.19 & 0.04 \\
\hline 31 & 0.18 & 0.22 & 0.24 & 0.04 & 0.32 \\
\hline 32 & 0.16 & 0.49 & 0.16 & 0.05 & 0.14 \\
\hline 33 & 0.23 & 0.16 & 0.05 & 0.50 & 0.06 \\
\hline 34 & 0.22 & 0.17 & 0.38 & 0.10 & 0.14 \\
\hline 35 & 0.35 & 0.35 & 0.15 & 0.05 & 0.10 \\
\hline 36 & 0.18 & 0.23 & 0.23 & 0.26 & 0.11 \\
\hline 37 & 0.32 & 0.32 & 0.14 & 0.08 & 0.14 \\
\hline 38 & 0.16 & 0.22 & 0.42 & 0.07 & 0.13 \\
\hline
\end{tabular}




\section{Abbreviations}

AHP: Analytic hierarchy process; ANP: Analytic network process; DEA: Data envelopment analysis; ELECTRE: ELimination Et Choix Traduisant la REalité: EU: European Union; GDP: Gross domestic product; TOPSIS: Technique for order preference by similarity to ideal solution (TOPSIS);

VIKOR: VIseKriterijumska Optimizacija I Kompromisno Resenje

\section{Acknowledgements}

The authors would like to thank 110 experts who were contacted for this study and 38 experts who provided detailed feedback to the questionnaires.

\section{Authors' contributions}

$G B$ is the first author of this article. GB has made substantial contributions to the conception and design of the work and has helped draft the work. GB has approved the submitted version and agreed both be personally accountable for his own contributions and to ensure that questions related to the accuracy or integrity of any part of the work are appropriately investigated, resolved, and the resolution documented in the literature. $X C$ is the second author and corresponding author of this article. XC has made substantial contributions to the interpretation of data and has substantively revised this article for submission. XC has approved the submitted version and agreed both to be personally accountable for his own contributions and to ensure that questions related to the accuracy or integrity of any part of the work are appropriately investigated, resolved, and the resolution documented in the literature. As the corresponding author, XC confirms that data/tables/figures/materials presentation accurately reflects the original. XC also confirms that the manuscript did not benefit from the use of editorial services. SC is the third author of this article. SC has made substantial contributions to the conception of the work and acquisition of data. SC has approved the submitted version and agreed both to be personally accountable for his own contributions and to ensure that questions related to the accuracy or integrity of any part of the work are appropriately investigated, resolved, and the resolution documented in the literature. BO is the fourth author of this article. BO has made substantial contributions to the acquisition and analysis of data and creation of the surveys. BO has approved the submitted version and agreed both to be personally accountable for his own contributions and to ensure that questions related to the accuracy or integrity of any part of the work are appropriately investigated, resolved, and the resolution documented in the literature. All authors read and approved the final manuscript.

\section{Funding}

Not applicable.

\section{Availability of data and materials}

All data generated or analyzed during this study are included in this article.

\section{Ethics approval and consent to participate}

Not applicable.

\section{Consent for publication}

Not applicable.

\section{Competing interests}

The authors declare that they have no competing interests.

Received: 30 April 2019 Accepted: 29 August 2019

Published online: 11 September 2019

\section{References}

1. Carli R, Dotoli M, Pellegrino R (2018) Multi-criteria decision-making for sustainable metropolitan cities. J Environ Manage 226:46-61

2. Carli R, Dotoli M, Pellegrino R (2017) A hierarchical decision-making strategy for the energy management of smart cities. IEEE Trans Autom Sci Eng 14:505-523

3. Lee CW, Zhong J (2014) Top down strategy for renewable energy investment: Conceptual framework and implementation. Renew Energy 68:761-773

4. Aguilar FX, Cai Z (2010) Exploratory analysis of prospects for renewable energy private investment in the U.S. Energy Econ 32:1245-1252
5. Zhang MM, Zhou P, Zhou DQ (2016) A real options model for renewable energy investment with application to solar photovoltaic power generation in China. Energy Econ 59:213-226

6. Simsek HA, Simsek N (2013) Recent incentives for renewable energy in Turkey. Energy Policy 63:521-530

7. Kılkış \$ (2015) Composite index for benchmarking local energy systems of Mediterranean port cities. Energy 92:622-638

8. Kılkıs \$ (2016) Sustainable development of energy, water and environment systems index for Southeast European cities. J Clean Prod 130:222-234

9. Mattiussi A, Rosano M, Simeoni P (2014) A decision support system for sustainable energy supply combining multi-objective and multi-attribute analysis: An Australian case study. Decis Support Syst 57:150-159

10. Romero SR, Santos AC, Gil MA (2012) EU plans for renewable energy: An application to the Spanish case. Renew Energy 43:322-330

11. Bulavskaya T, Reynès $F$ (2018) Job creation and economic impact of renewable energy in the Netherlands. Renew Energy 119:528-538

12. Saaty TL (2008) Decision making with the analytic hierarchy process. Int J Serv Sci 1:83-98

13. Saaty TL (1990) How to make a decision: the analytic hierarchy process. Eur J Oper Res 48:9-26

14. Vargas LG (1990) An overview of the analytic hierarchy process and its applications. Eur J Oper Res 48:2-8

15. Akash BA, Mamlook R, Mohsen MS (1999) Multi-criteria selection of electric power plants using analytical hierarchy process. Electr Power Syst Res 52:29-35

16. Amer M, Daim TU (2011) Selection of renewable energy technologies for a developing county: A case of Pakistan. Energy Sustain Dev 15:420-435

17. Daniel J, Vishal NVR, Albert B, Selvarsan I (2010) Evaluation of the significant renewable energy resources in India using Analytical Hierarchy Process. In: Ehrgott M, Naujoks B, Stewart T, Wallenius J (eds) Multiple criteria decision making for sustainable energy and transportation systems. Springer, Berlin; Heidelberg, pp 13-26

18. Demirtas $O$ (2013) Evaluating the best renewable energy technology for sustainable energy planning. Int J Energy Econ Policy 3:23-33

19. Kabir ABMZ, Shihan SMA (2003) Selection of renewable energy sources using Analytic Hierarchy Process. Proceeding of the 7th International Symposium on the Analytic Hierarchy Process, Bali, pp 267-276

20. Kaya T, Kahraman C (2010) Multicriteria renewable energy planning using an integrated fuzzy VIKOR \& AHP methodology: the case of Istanbul. Energy 35:2517-2527

21. Løken E (2007) Use of multicriteria decision analysis methods for energy planning problems. Renew Sustain Energy Rev 11:1584-1595

22. Nigim K, Munier N, Green J (2004) Pre-feasibility MCDM tools to aid communities in prioritizing local viable renewable energy sources. Renew Energy 29:1775-1791

23. Pohekar SD, Ramachandran M (2004) Application of multi-criteria decision making to sustainable energy planning-A review. Renew Sustain Energy Rev 8:365-381

24. Yazdani-Chamzini A, Fouladgar MM, Zavadskas EK, Moini SHH (2013) Selecting the optimal renewable energy using multi criteria decision making. J Bus Econ Manag 14:957-978

25. Sindhu SP, Nehra V, Luthra S (2016) Recognition and prioritization of challenges in growth of solar energy using analytical hierarchy process: Indian outlook. Energy 100:332-348

26. Uyan M (2013) GIS-based solar farms site selection using analytic hierarchy process (AHP) in Karapinar region, Konya/Turkey. Renew Sust Energ Rev 28:11-17

27. Papalexandrou MA, Pilavachi PA, Chatzimouratidis Al (2008) Evaluation of liquid bio-fuels using the Analytic Hierarchy Process. Process Saf Environ Prot 86:360-374

28. Okello C, Pindozzi S, Faugno S, Boccia L (2014) Appraising bioenergy alternatives in Uganda using strengths, weaknesses, opportunities and threats (SWOT)-analytical hierarchy process (AHP) and a desirability functions approach. Energies 7:1171-1192

29. Choudhary D, Shankar R (2012) An STEEP-fuzzy AHP-TOPSIS framework for evaluation and selection of thermal power plant location: a case study from India. Energy 42:510-521

30. Peng J (2012) Research on the optimization of green suppliers based on AHP and GRA. Int J Inf Comput Sci 9:173-182

31. Chiu R-H, Lin L-H, Ting SC (2014) Evaluation of green port factors and performance: a fuzzy AHP analysis. Math Probl Eng 5:1-12 
32. Cheng C, Zhou Y-H, Yue K-W, Yang J, He Z-Y, Liang N (2011) Study of SEA indicators system of urban green electricity power based on fuzzy AHP and DPSIR model. Energy Procedia 12:155-162

33. Aras H, Erdoğmuş Ş, Koç E (2004) Multi-criteria selection for a wind observation station location using analytic hierarchy process. Renew Energ 29:1383-1392

34. Lee SK, Mogi G, Hui KS (2013) A fuzzy analytic hierarchy process (AHP)/data envelopment analysis (DEA) hybrid model for efficiently allocating energy R\&D resources: In the case of energy technologies against high oil prices. Renew Sust Energ Rev 21:347-355

35. Mohsen MS, Akash BA (1997) Evaluation of domestic solar water heating system in Jordan using analytic hierarchy process. Energy Convers Manag 38:1815-1822

36. Afgan NH, Carvalho MG (2002) Multi-criteria assessment of new and renewable energy power plants. Energy 27:739-755

37. Budak G, Kara I, İ Y YT (2017) Weighting the positions and skills of volleyball sport by using AHP: A real life application. IOSR J Sports Phys Educ 4:23-29

38. Saaty TL (1990) Decision making for leaders: the analytic hierarchy process for decisions in a complex world. RWS Publications

39. Acaroglu H, Baykul MC (2019) Economic guideline about financial utilization of flat-plate solar collectors for the consumer segment in the city of Eskisehir. Renew Sust Energ Rev 81:2045-2058

40. U.S. Energy Information Administration. Illinois State Profiles and Energy Estimates, https://www.eia.gov/state/?sid=IL; 2019 [accessed 13 Mar 2019]

41. Illinois Commerce Commission. Environmental Disclosure Statements, https://www.icc.illinois.gov/electricity/utilityreporting/ environmentaldisclosurearchive.aspx; 2011 [accessed 13 Mar 2019].

\section{Publisher's Note}

Springer Nature remains neutral with regard to jurisdictional claims in published maps and institutional affiliations.

Ready to submit your research? Choose BMC and benefit from:

- fast, convenient online submission

- thorough peer review by experienced researchers in your field

- rapid publication on acceptance

- support for research data, including large and complex data types

- gold Open Access which fosters wider collaboration and increased citations

- maximum visibility for your research: over $100 \mathrm{M}$ website views per year

At BMC, research is always in progress.

Learn more biomedcentral.com/submissions 